\title{
High-resolution monitoring of marine protists based on an observation strategy integrating automated on-board filtration and molecular analyses
}

\author{
Katja Metfies $^{1}$, Friedhelm Schroeder ${ }^{2}$, Johanna Hessel ${ }^{1}$, Jochen Wollschläger ${ }^{2}$, Sebastian Micheller ${ }^{1}$, Christian Wolf $^{1}$, \\ Estelle Kilias $^{1}$, Pim Sprong ${ }^{1}$, Stefan Neuhaus ${ }^{3}$, Stephan Frickenhaus ${ }^{3}$, and Wilhelm Petersen ${ }^{2}$ \\ ${ }^{1}$ Helmholtz Young Investigators Group PLANKTOSENS, Alfred Wegener Institute Helmholtz Centre for Polar and Marine \\ Research, 27570 Bremerhaven, Germany \\ ${ }^{2}$ In-situ Measuring Systems, Helmholtz Zentrum Geesthacht Centre for Materials and Coastal Research, \\ 21502 Geesthacht, Germany \\ ${ }^{3}$ Scientific Computing, Alfred Wegener Institute Helmholtz Centre for Polar and Marine Research, \\ Bremerhaven, 27570 Bremerhaven, Germany
}

Correspondence to: Katja Metfies (katja.metfies@awi.de)

Received: 30 April 2016 - Published in Ocean Sci. Discuss.: 23 May 2016

Revised: 30 August 2016 - Accepted: 12 September 2016 - Published: 22 November 2016

\begin{abstract}
Information on recent biomass distribution and biogeography of photosynthetic marine protists with adequate temporal and spatial resolution is urgently needed to better understand the consequences of environmental change for marine ecosystems. Here we introduce and review a molecular-based observation strategy for high-resolution assessment of these protists in space and time. It is the result of extensive technology developments, adaptations and evaluations which are documented in a number of different publications, and the results of the recently completed field testing which are introduced in this paper. The observation strategy is organized at four different levels. At level 1, samples are collected at high spatiotemporal resolution using the remotely controlled automated filtration system AUTOFIM. Resulting samples can either be preserved for later laboratory analyses, or directly subjected to molecular surveillance of key species aboard the ship via an automated biosensor system or quantitative polymerase chain reaction (level 2). Preserved samples are analyzed at the next observational levels in the laboratory (levels 3 and 4). At level 3 this involves molecular fingerprinting methods for a quick and reliable overview of differences in protist community composition. Finally, selected samples can be used to generate a detailed analysis of taxonomic protist composition via the latest next generation sequencing technology (NGS) at level 4. An over-
\end{abstract}

all integrated dataset of the results based on the different analyses provides comprehensive information on the diversity and biogeography of protists, including all related size classes. At the same time the cost of the observation is optimized with respect to analysis effort and time.

\section{Introduction}

It is expected that marine ecosystems will be affected by climate change in multiple ways, including rising atmospheric $\mathrm{CO}_{2}$ levels, shifts in temperature, circulation, stratification, nutrient input, oxygen content, and ocean acidification. In summary, these changes will strongly impact marine biota and ecosystems with consequences for abundance, diversity, spatial distribution, biogeography, or dominance of marine species (Doney et al., 2012). Marine plankton, comprising prokaryotic and eukaryotic microbes (bacteria and protists) as well as small or juvenile metazoans, is of utmost importance for the functioning of marine ecosystems. It is traditionally divided by its size into three classes: The microplankton $(20-200 \mu \mathrm{m})$, the nanoplankton $(20-2 \mu \mathrm{m})$, and the picoplankton $(<2 \mu \mathrm{m})$. Within these groups of organisms, phytoplankton (as the photosynthetically active part of the plankton) accounts for roughly half of global net primary 
productivity (NPP) (Field et al., 1998) and is fundamental for any marine ecosystem function or service. As a consequence, changes in phytoplankton community structures and biogeography as a response to climate change are currently topical issues in marine ecology. Moreover, marine phytoplankton is very well suited to serve as an indicator of climate change (Nehring, 1998), because its dynamics are closely coupled to environmental conditions (AcevedoTrejos et al., 2014). Despite the necessity and advantage of using marine phytoplankton to assess consequences of climate change, the task is also challenging in various ways. Marine phytoplankton distribution displays high spatial heterogeneity, or "patchiness" (Mackas et al., 1985), and a pronounced seasonality as a consequence of physical and chemical oceanographic processes (Boersma et al., 2016; Bresnan et al., 2015). Furthermore, there are difficulties with the taxonomic surveillance of species in the pico- or nano-fraction, related to their cell size and insufficient morphological features (e.g., Caron et al., 1999). As a consequence it is very challenging to provide information on composition, occurrence, and dynamics of phytoplankton with adequate spatial and temporal resolution. Together with the difficulties of financially supporting and maintaining long-term series, these challenges might account for the relatively small number of marine phytoplankton long-term time series worldwide. Among them, one long-lasting time series, the Helgoland Roads time series, is maintained by the Alfred Wegener Institute Helmholtz Centre for Polar and Marine Research at the island Helgoland in the German Bight (North Sea). The dataset comprises information on abundance of phytoplankton on a daily basis since 1962 (Kraberg et al., 2015; Wiltshire et al., 2009). However, it does not provide information on the abundance of the smallest phytoplankton species and is restricted to one sampling point. The latter restriction is overcome by a second major long-term marine observation programme that is operated by the Sir Alistair Hardy Foundation for Ocean Science in Plymouth, UK: the Continuous Plankton Recorder (CPR) survey's marine observation programme (McQuatters-Gollop et al., 2015). Together with its sister surveys it has provided large-scale information on marine plankton distribution, mainly in the North Atlantic and the North Sea, since the first surveys in 1931. Unfortunately, the CPR approach is restricted to zooplankton and larger phytoplankton (e.g., diatoms). Again, the ecologically relevant pico-phytoplankton fraction is omitted. However, the smaller phytoplankton is to a certain degree included in the surveys of the FerryBox project implemented by the Helmholtz Centre Geesthacht in the North Sea. A FerryBox is an autonomous device located on "ships of opportunity" that has the capability to autonomously generate information on the plankton composition, and a number of other parameters, of the North Sea (Petersen, 2014). Here, phytoplankton is characterized on the basis of the pigment composition present, which is estimated via multi-channel fluorescence measurements. All phytoplankton groups and size fractions are in- cluded in this analysis, but this approach is only suited for the identification of larger taxonomic algal groups. Furthermore, spectrally similar groups (e.g., diatoms and dinoflagellates) cannot be distinguished by this method. Thus the FerryBox project lacks information on species composition of phytoplankton.

Overall, these long-term monitoring programmes and other current marine plankton observation approaches have already given important information on, and indication of, climate-related change in the marine plankton community. Nevertheless, each of them is limited in one way or another: (i) the ongoing long-term series are mainly limited to one or small numbers of sampling points; (ii) they do not provide a holistic view of changes at the base of marine food webs, because they neglect the pico- and most of the nanophytoplankton; (iii) broad taxonomic knowledge is required for the identification of taxa at species level; (iv) fluorescent characterization of phytoplankton is restricted to the identification of larger taxonomic groups; (v) they are costly if larger numbers of samples need to be processed. To address these shortcomings and challenges of current observation approaches, it is of the utmost importance to develop efficient automated high-throughput approaches and observation strategies that allow reliable surveillance of all phytoplankton size classes with adequate spatiotemporal resolution. Over the past decade numerous publications demonstrated the power of molecular methods for the observation of marine plankton organisms, especially of those that are missing distinct morphological features (Metfies et al., 2010; Wolf et al., 2014a; Wollschläger et al., 2014). Previous publications have shown the power of the analysis of ribosomal genes (rRNA genes) to gain new insights into the phylogeny and biogeography of prokaryotic and eukaryotic micro-organisms (Comeau et al., 2011; Sunagawa et al., 2015). The genes coding for the rRNA are particularly well suited for phylogenetic analysis and taxonomical identification, because they are universally present in all cellular organisms. Furthermore, rRNA genes are of relatively large size and contain both highly conserved and variable regions with no evidence for lateral gene transfer (Woese, 1987). The continually growing number of available algal 18S rDNA sequences, e.g., in the Ribosomal Database Project (Quast et al., 2013), and phylogenetic analysis make it possible to design hierarchical sets of probes that specifically target the 18S rDNA of different taxa (Metfies and Medlin, 2007; Thiele et al., 2014). The probes can be used in combination with a wide variety of hybridization-based methods, such as RNA-based nucleic acid biosensors (Diercks et al., 2008a; Ussler et al., 2013), quantitative polymerase chain reaction (PCR) (Bowers et al., 2010; Toebe et al., 2013), or fluorescence in situ hybridization (FISH) (Thiele et al., 2014) to identify marine microbes. Other methods, such as molecular fingerprinting approaches and next generation sequencing (NGS), provide information on variability and composition of whole microbial communities. The molecular fingerprint- 
ing method automated ribosomal intergenic spacer analysis (ARISA) is a quick, cost-effective, and meaningful method of determining overall variability in phytoplankton community composition (Kilias et al., 2015) that is independent of the size or morphology of target organisms. In contrast, NGS of ribosomal genes allows high-resolution, taxon-specific assessments of protist communities, including their smallest size fractions and the rare biosphere (de Vargas et al., 2015; Kilias, 2014b, c).

Here, we introduce a combined molecular-based observation strategy that allows observation of current phytoplankton composition, distribution, and dynamics at adequate spatial and temporal scales. The resulting datasets can be used to estimate possible alterations related to climate or environmental change. Our strategy is the result of technical developments and the integration of the latest sampling and molecular tools in an advanced molecular-based observation approach that will optimize marine microbial observation in general, while phytoplankton was the focus of our developments. In the future our molecular observation strategy is intended to cut down surveillance costs and provide information on marine microbial biodiversity with unprecedented resolution. It is a development of the Helmholtz Young Investigators Group PLANKTOSENS (Assessing Climate Related Variability and Change of Planktonic Foodwebs in Polar Regions and the North Sea), carried out within the framework of COSYNA (Coastal Observing System for Northern and Arctic Seas). Here, we review major published results that lead to the development of the molecular observation strategy and demonstrate the applicability of newly developed sampling technology within the observation strategy. Special emphasis was put on observation of Arctic pico-phytoplankton that constitutes a major contribution to pelagic Chl $a$ biomass during summer (Metfies et al., 2016).

\section{Material and methods}

\subsection{Sampling}

Water samples analyzed in this study were collected during expeditions PS85 (June 2014) and PS96 (May/June 2015) of RV Polarstern to the Arctic Ocean. Samples from deeper water layers containing the deep chlorophyll maximum (DCM) were taken with a rosette sampler equipped with 24 Niskin bottles (12 L per bottle) and sensors for Chl $a$ fluorescence, temperature, and salinity (CTD). Samples collected via CTD were taken during the up-casts at the vertical maximum of $\mathrm{Chl} a$ fluorescence determined during the down-casts. The sampling depths varied between 10 and $50 \mathrm{~m}$. Two liters of water subsamples were taken in PVC bottles from the Niskins. Particulate organic matter for molecular analyses was collected by sequential filtration of one water sample through three different mesh sizes $(10,3,0.4 \mu \mathrm{m})$ on $45 \mathrm{~mm}$ diameter Isopore Membrane Filters at 200 mbar using a Mil- lipore Sterifil filtration system (Millipore, USA). Subsequent to sampling, the filters were stored at $-20^{\circ} \mathrm{C}$ until further analyses.

Additional samples were collected from a depth of $\sim 10 \mathrm{~m}$ with the automated filtration device for marine microorganisms (AUTOFIM), which is coupled to the ship's pump system. Fitting and programming of the device does not require special expertise if it is done according to the manufacturer's protocol. All steps related to the filtration process, including application of Lysis Buffer RLT (Qiagen, Germany), were carried out automatically by AUTOFIM. In this study, two liters of sea water were collected and filtrated on a filter with $0.4 \mu \mathrm{m}$ pore size at $200 \mathrm{mbar}$. Subsequent to filtration, particulate organic matter on the filter was re-suspended with $600 \mu \mathrm{L}$ Lysis Buffer RLT (Qiagen, Germany) and stored at $-80^{\circ} \mathrm{C}$ until further processing in the laboratory. The filtration device was cleaned after each filtration step by rinsing the device with fresh water.

\subsection{Environmental parameters}

Standard oceanographic parameters (salinity, temperature, Chl $a$ fluorescence, turbidity, chromophoric dissolved organic matter, dissolved oxygen, $\mathrm{pH}$, nutrients) were measured at the sampling sites by the FerryBox System (Petersen, 2014) deployed on board RV Polarstern. The measurement interval was $1 \mathrm{~min}$, and the water intake of the system was identical to the water supply of AUTOFIM. To prevent biofouling of the sensors, the FerryBox performed a cleaning cycle including an acid wash and freshwater rinsing once per day.

\subsection{DNA isolation}

Isolation of genomic DNA from the field samples was carried out using the E.Z.N.A TM SP Plant DNA Kit Dry Specimen Protocol (Omega Bio-Tek, USA), following the manufacturer's protocol. The resulting DNA-extracts were stored at $-20^{\circ} \mathrm{C}$.

\subsection{DNA quality}

The integrity of the genomic DNA isolated from water samples collected with AUTOFIM was assessed using the Agilent DNA 7500 kit (Agilent Technologies, USA) according to the manufacturer's protocol. A volume of $1 \mu \mathrm{L}$ DNA was applied to the flow cell.

\subsection{ARISA}

PCR amplification and subsequent determination of the size of the PCR fragments, as well as statistical analyses related to ARISA, were accomplished as described previously in the studies contributing to the development of the molecular observation strategy (e.g., Kilias et al., 2015). This included the determination of variability in the length of the internal tran- 
scribed spacer 1 (ITS1), amplified via a specific primer set from genomic DNA extracted from field samples.

\subsection{4 pyrosequencing}

Sequencing of protist communities via 454 pyrosequencing was based, in all studies reviewed in this paper, on amplification of a $\sim 670 \mathrm{bp}$ fragment of the 18S rDNA containing the hypervariable V4 region. Sequence library preparation and data analysis were described previously in the studies contributing to the development of the molecular observation strategy (Kilias et al., 2013; Metfies et al., 2016). Thus, for more detailed information, the reader is referred to these publications.

\subsection{Quantitative PCR assay}

The quantitative PCR was carried out in a nested two-step approach. We used this nested approach because it minimized the variability between technical replicates of qPCR data obtained from analyses of field samples. The applicability of the nested approach was evaluated by a comparison of qPCR data with manual counts of Phaeocystis pouchetii in field samples (data not shown). In the first step total eukaryotic 18S rDNA was amplified from a positive control (genomic DNA Phaeocystis pouchetii), a negative control (no template), and genomic DNA isolated from field samples using the universal primer set $1 \mathrm{~F}-\left(5^{\prime}\right.$-AAC TGG TTG ATC CTG CCA GT- $\left.3^{\prime}\right) / 1528 \mathrm{R}-\left(5^{\prime}\right.$-TGA TCC TTC TGC AGG TTC ACC TAC-3') (modified after Medlin et al., 1988). PCR amplifications were performed in a $20 \mu \mathrm{L}$ volume in a thermal cycler (Eppendorf, Germany) using $1 \times$ HotMaster Taq buffer containing $\mathrm{Mg}^{2+}, 2.5 \mathrm{mM}$ (5'Prime), $0.5 \mathrm{U}$ HotMaster Taq polymerase (5'Prime, Germany), $0.4 \mathrm{mg} \mathrm{mL}^{-1}$ BSA; $0.8 \mathrm{mM}$ (each) dNTP (Eppendorf, Germany), $0.2 \mu \mathrm{M}$ of each primer $\left(10 \mathrm{pmol} \mu \mathrm{L}^{-1}\right)$, and $1 \mu \mathrm{L}$ of template DNA (20 ng $\left.\mu \mathrm{L}^{-1}\right)$. The amplification was based on 35 cycles, consisting of $94^{\circ} \mathrm{C}$ for $1 \mathrm{~min}, 54^{\circ} \mathrm{C}$ for $2 \mathrm{~min}$, and $72^{\circ} \mathrm{C}$ for $2 \mathrm{~min}$, followed by $1 \mathrm{~min}$ denaturation at $94^{\circ} \mathrm{C}$ and finalized by a final extension of $10 \mathrm{~min}$ at $72^{\circ} \mathrm{C}$. Subsequently PCR products were purified using the QIAquick PCR purification kit (Qiagen, Hilden, Germany). In the second step a qPCR-assay was carried out using a species-specific primer set 82F-(5'-GTG AAA CTG CGA ATG GCT CAT-3')/P1np(5'-CGG GCG GAC CCG AGA TGG TT-3') for Phaeocystis pouchetii. The quantitative PCR assays were performed in triplicate in a $20 \mu \mathrm{L}$ volume in a 7500 Fast Real-Time PCR System (Life Technologies Corporation; Applied Biosystems, USA) using $1 \times$ SYBR Select Mastermix (Life Technologies, USA), $0.2 \mu \mathrm{M}$ of each primer $\left(10 \mathrm{pmol} \mu \mathrm{L}^{-1}\right)$, and $2 \mu \mathrm{L}$ of the purified $18 \mathrm{~S}$ rDNA PCR fragment. The amplification was based on 40 cycles, consisting of $95^{\circ} \mathrm{C}$ for $10 \mathrm{~min}$, $95^{\circ} \mathrm{C}$ for $15 \mathrm{~s}$, and $66^{\circ} \mathrm{C}$ for $1 \mathrm{~min}$. The quantitative PCR assay was calibrated with a dilution series of a laboratory culture of Phaeocystis pouchetii (Fig. 4). Based on this cal- ibration CT values were transformed into cell numbers using the following equation: $\mathrm{CT}=-2.123 \ln$ (cell numbers) +38.788 .

\section{Results and discussion}

\subsection{Overview of molecular-based observation strategy}

The molecular-based observation strategy that we present here is organized into 4 different levels (Fig. 1). At level 1, samples are collected in high spatiotemporal resolution using AUTOFIM (Fig. 2). The sampling system can either be deployed on a fixed monitoring platform or aboard a ship (research vessel or ship of opportunity) without the need for a highly trained person. Samples can be preserved with a preservation buffer (e.g., DNAgard, Biomatrica, USA) for later laboratory analyses, or directly subjected to molecular surveillance of key species aboard the ship via an automated biosensor system or quantitative polymerase chain reaction (level 2). Direct analyses aboard ships provide near-real-time information on abundance and distribution of phytoplankton key species, which can be used to optimize phytoplankton sampling for detailed high-resolution analyses of overall phytoplankton composition during an ongoing sampling campaign. The resulting preserved samples will be analyzed at the next observational levels in the laboratory (levels 3 and 4). At level 3 this involves molecular fingerprinting methods that provide a quick and reliable overview of differences in protist community composition of the samples in a given observation area or time period. Furthermore, this information can be used to select representative samples for detailed analysis of taxonomic protist composition via the latest next generation sequencing at level 4 . An overall integrated dataset of the results based on the different analyses provides comprehensive information on the diversity and biogeography of protists, including all related size classes. At the same time, the cost of the observation is optimized with respect to analysis effort and time. Sampling based on the autonomous filtration device is more cost efficient because labor costs and the requirement of ship space and time are reduced.

The development of the molecular observation strategy was based on extensive method development and evaluation. Overall, it included: (i) the development of an automated remotely controlled filtration system (Fig. 2), (ii) the evaluation and application of Automated Ribosomal Intergenic Spacer Analysis (ARISA) (Kilias et al., 2015), (iii) the implementation of next generation sequencing (454 pyrosequencing; Illumina) for marine protists (e.g., Wolf et al., 2013), and (iv) the development and evaluation of molecular-probebased methods such as molecular sensors (Wollschläger et al., 2014) or quantitative PCR (qPCR). Most of the field work presented here in this publication was accomplished in the Arctic Ocean with special emphasis on the area of the deepsea long-term observatory "Hausgarten", established in 1999 

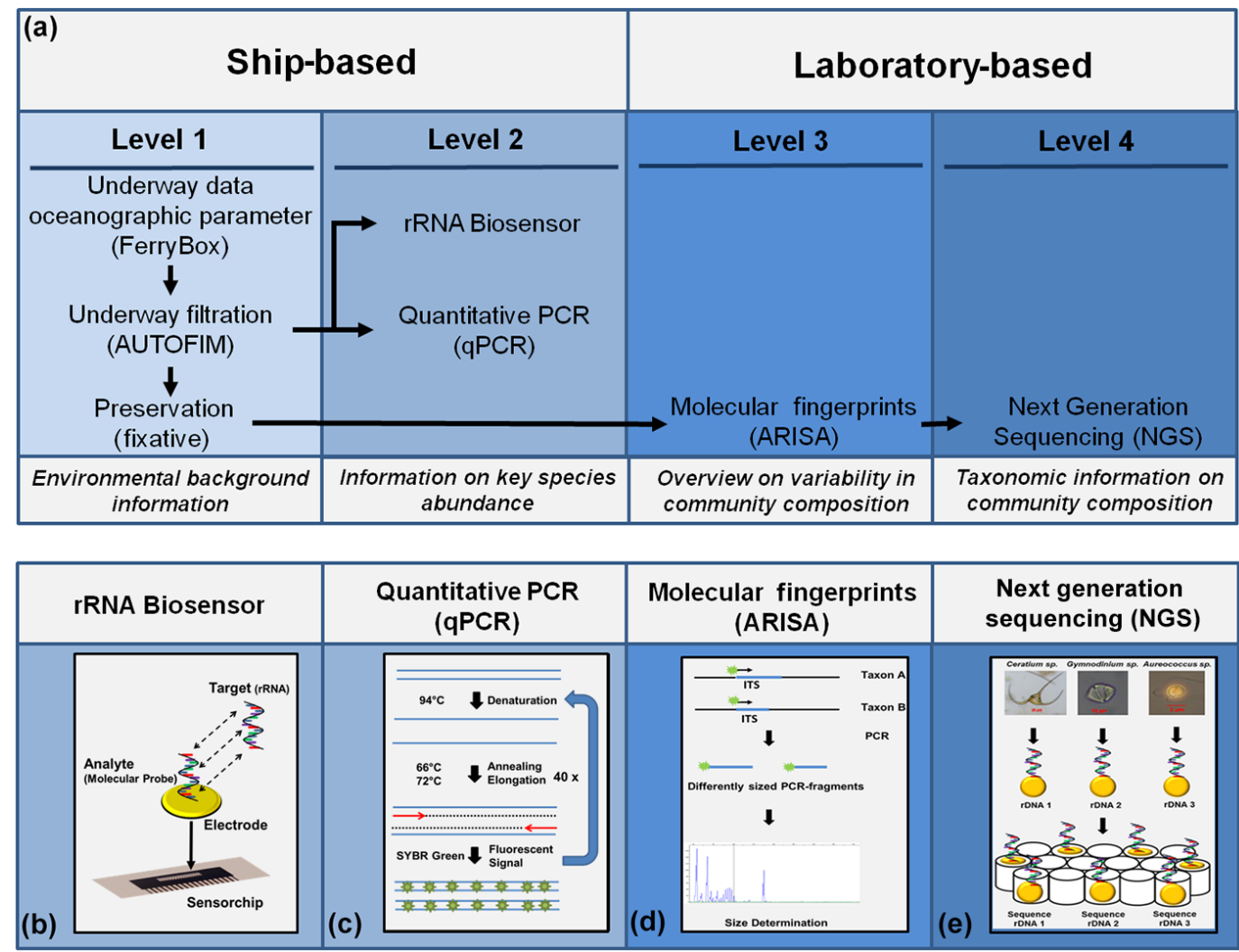

Figure 1. (a) Overview of the smart observation strategy which is organized into four different levels: level 1: samples are collected in transit or at monitoring sites using the remotely controlled automated filtration system AUTOFIM; level 2: direct molecular surveillance of key species aboard the ship via an automated biosensor system or quantitative polymerase chain reaction; level 3: preserved samples are analyzed via molecular fingerprinting methods (e.g., ARISA) that provide a quick and reliable overview of differences in protist community composition of the samples in a given observation area or time period; level 4: detailed analysis of taxonomic protist composition in selected samples via the latest next generation sequencing. (b-e) Schematic diagrams illustrating the analyses used in the smart observation strategy.

by the Alfred Wegener Institute for Polar and Marine Research to carry out regular observations of the ecosystem in the eastern Fram Strait (Soltwedel, 2005). In the following, the different parts of the observation strategy are presented in detail.

\subsubsection{Automated remotely controlled filtration system}

The remotely controlled automated filtration system for marine microbes (AUTOFIM) is the core of the observation strategy. The filtration system (Fig. 2) can be operated autonomously aboard research vessels or ships of opportunity. AUTOFIM allows filtration of a sampling volume up to five liters from the upper water column. In total, 12 filters can be taken and stored in a sealed sample archive. Prior to storage, a preservative such as Lysis Buffer RLT (Qiagen, Germany) is applied to the filters, preventing degradation of the sample material, which can be used for molecular or biochemical analyses. Exchanging the sample archive is a quick and easy task, which makes it feasible for lay persons from the ships' staff to take care of the automated filtration. This would circumvent the need to provide support of an additional specifically trained person for filtration in the field. Filtration can be triggered after defined regular time intervals or remotely controlled from a scientist at the research institute. Additionally, it could also be event-triggered if the filtration system were operated in connection with in situ sensor systems (Petersen, 2014). Overall, AUTOFIM provides the technical background for automated high spatiotemporal resolution collection of marine particles, e.g., for molecular analyses. During expedition PS92 of RV Polarstern to the Arctic Ocean in summer 2015, AUTOFIM was used for the first time to collect samples from the upper water column at a depth of $\sim 10 \mathrm{~m}$, which is the depth of the inlet of the ship's water pump system. Subsequent to filtration, samples were preserved with a preservation buffer and stored at $-80^{\circ} \mathrm{C}$ until further analyses in the laboratory. 


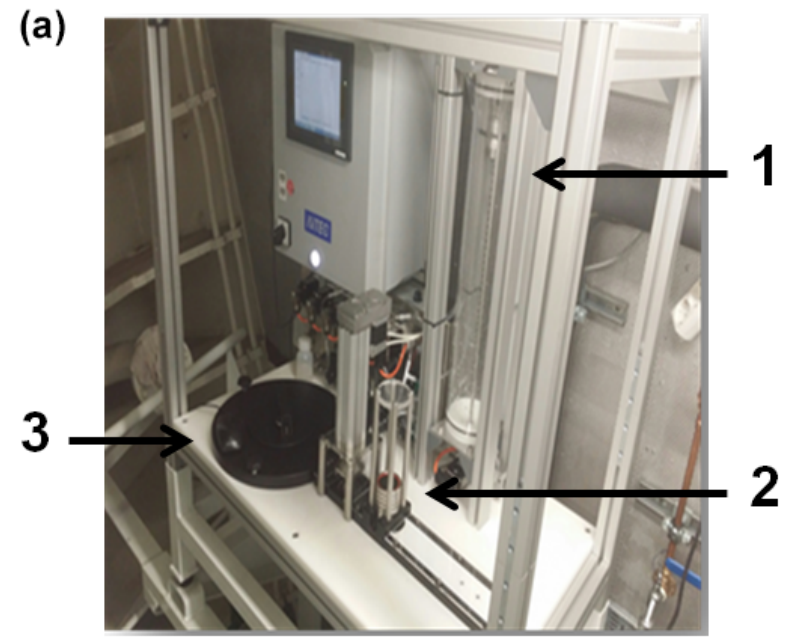

(b)

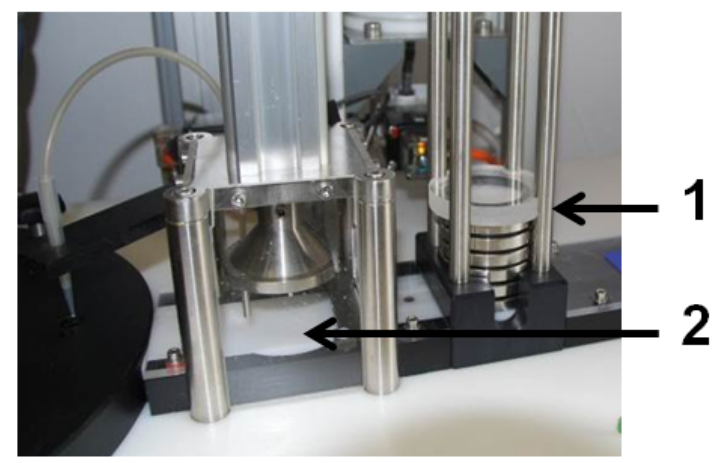

Figure 2. (a) AUTOFIM installed on board RV Polarstern (1: Sample reservoir; 2: Filtration; 3: Archive for preserved filters). (b) Filtration-module (1: Filter stacker; 2: Filtration cap).

\subsubsection{Automated ribosomal intergenic spacer analysis (ARISA)}

ARISA provides information on variability in protist community structure in larger sample sets at reasonable costs and effort. In an ARISA the community is characterized by its community profile, which is based on the composition (presence/absence) of differently sized DNA fragments. The DNA fragments are a result of the amplification of the internal transcribed spacer region of the ribosomal operon, which displays a high degree of taxon-related variability in its length. ARISA profiles reflect taxon-specific differences observed in NGS datasets (Kilias et al., 2015). In the developmental phase of the molecular observation strategy, this method was used in a number of different studies to better understand variability of Arctic marine protist communities in relation to environmental conditions and ocean currents. Based on ARISAs, we identified large-scale patterns of protist biogeography that were tightly connected to ambient water masses, ocean currents, and sea-ice coverage (Kilias et al., 2014a; Metfies et al., 2016; Wolf et al., 2014b). We suggest using ARISA as part of the molecular observation strategy to identify biogeographic or biodiversity patterns in large sample sets, e.g., those collected via AUTOFIM. Identification of patterns in phytoplankton biogeography or biodiversity requires analyses of large sample sets, because spatial heterogeneity of marine phytoplankton is considerable, while the vertical dimension is of particular importance, since differences in vertical abundance and composition of phytoplankton impact primary production, export processes, and energy transfer to higher trophic levels (Leibold, 1990). Vertical distribution of marine protists is determined by opposing resource gradients and mixing conditions (Mellard et al., 2011). With respect to this it was necessary to evaluate how representative samples from $10 \mathrm{~m}$ depth might be of the photic zone in the underlying water column. This is important in case AUTOFIM is applied to study large-scale biogeographic patterns of marine protists. Acknowledging the potential of ARISA to quickly generate meaningful information on variability between protist samples, we used this methodology in this study to assess the similarity of phytoplankton community composition in samples from the upper water column collected with AUTOFIM and in samples collected in deeper water layers via CTD at the same location. The ARISA patterns obtained from deeper water layers $(20$, $50 \mathrm{~m}$ ) are highly similar to those obtained from the samples collected with AUTOFIM. The samples collected with AUTOFIM at stations PS92/19 and PS92/43 clustered together with the individual samples collected at other depths at the same location $(5,20,50 \mathrm{~m})$ and with the integrated signal from the CTD sampling (all three depths) at this location (Fig. 3). This result suggests that qualitative information on phytoplankton community composition, based on sampling with AUTOFIM, can be considered as representative of the photic layer of the water column. This might be attributed to the observation that geography and ambient water masses have a major impact on qualitative composition of marine plankton communities on a larger scale, with plankton communities being partially structured according to the basin of origin (de Vargas et al., 2015; Metfies et al., 2016).

\subsubsection{Next generation sequencing (454 pyrosequencing; Illumina)}

Sequencing of ribosomal genes is a valuable approach to describe the taxonomic composition of protist communities, including the small size fractions. Technical progress in this field has been tremendously rapid over the last 5-10 years. Around 10 to 15 years ago, sequencing of $18 \mathrm{~S}$ rDNA clone libraries was the gold standard for assessing marine eukaryotic and prokaryotic communities (Hugenholtz, 2002). Around six years ago, the first studies reported the use of 454 pyrosequencing for assessment of prokaryotic diversity (Turnbaugh et al., 2009). The massively parallel 454 pyrosequencing was found to generate several hundred thousands of ribosomal sequences per sample and had the potential to uncover 


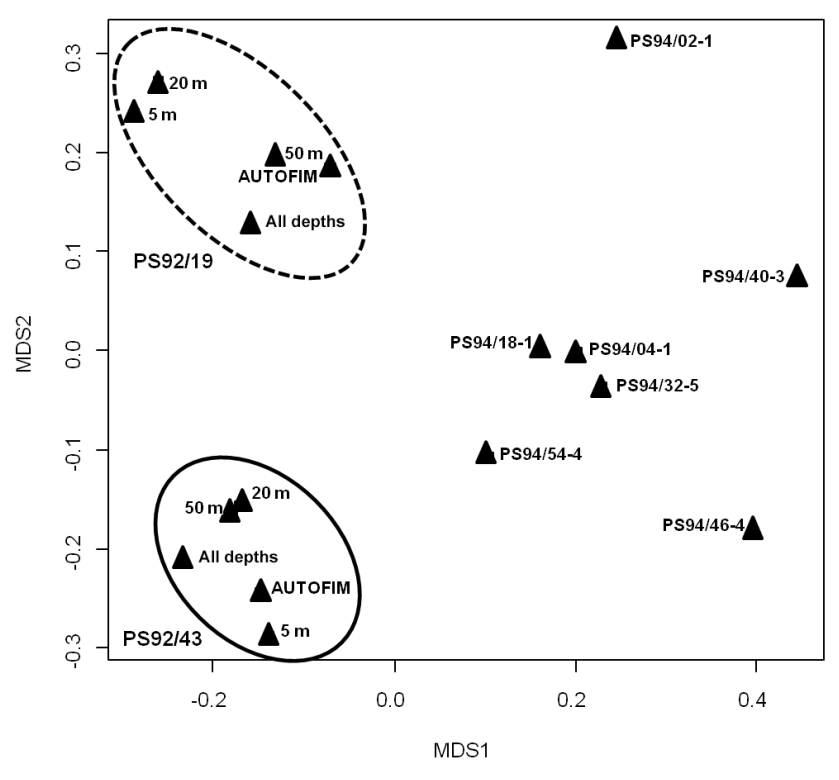

Figure 3. MetaMDS plot (non-metric multidimensional scaling plot) of ARISA fingerprints generated from samples collected via Niskin bottles coupled to a CTD rosette and AUTOFIM. The closer the samples are located to each other in the metaMDS plot, the more similar the ARISA profiles of the samples are. The label of the samples gives information on the cruise leg (PSXX) and the station (/XX). Samples were collected during expeditions PS92 and PS94 of RV Polarstern to the Arctic Ocean during summer 2015. The samples collected during PS94 serve as an outgroup in this analysis.

more organisms, even rare species from large-scale biodiversity surveys (Sunagawa et al., 2015). We assessed the validity of 454 pyrosequencing by evaluating the sequence datasets with results obtained via other methods, such as $18 \mathrm{~S}$ clone libraries, HPLC, and microscopic counts. The samples analyzed in the course of this evaluation originated from the same Niskin bottle of a respective CTD cast. In our datasets pyrosequencing data were in good agreement with information on community composition generated by high-pressure liquid chromatography (HPLC) or clone libraries (Kilias et al., 2013; Wolf et al., 2013). During the past six years, we used 454 pyrosequencing to determine the variability of protist community structure in the Fram Strait, in the area of the deep-sea long-term observatory Hausgarten, and the central Arctic Ocean (Kilias et al., 2014a; Metfies et al., 2016). Overall, our data revealed that Phaeocystis pouchetii is an important contributor to Arctic protist communities, particularly to the pico-eukaryote community composition. In 2009 the species constituted up to $29.6 \%$ of the sequence assemblage retrieved from pico-eukaryote samples in that area (Kilias et al., 2014b). A larger survey of Arctic protist community composition in 2012, including the Fram Strait and larger parts of the central Arctic Ocean, confirmed these observations and identified Phaecystis pouchetii once again as an important contributor to Arctic pico-eukaryote $\mathrm{Chl} a$ biomass.
The latter constituted between 60 and $90 \%$ of $\mathrm{Chl} a$ biomass during summer 2012 in the Arctic Ocean (Metfies et al., 2016). This comprehensive sequence-based information on phytoplankton community composition was very well suited to serve as a basis for the development of molecular probes that can be used for molecular surveillance with molecular sensors or qPCR.

\subsubsection{Development and evaluation of molecular-probe-based methods: molecular sensors or qPCR}

Molecular sensors are chip-based formats that allow parallel identification and quantification of multiple taxa in a single experiment. The identification is based on solid phase hybridization of molecular probes, immobilized to the surface of the sensor chips that bind to the rRNA or rDNA of the target species (Diercks et al., 2008a, b; Ussler et al., 2013). Quantitative, or real-time, PCR is a PCR-based method that utilizes fluorescent dyes or fluorescently labeled molecular probes to quantify nucleic acids after each PCR cycle. It is a useful tool for quantitation of nucleic acids or species in a given environment (Toebe et al., 2013). An automated molecular sensor (Diercks et al., 2008a) and qPCR are intended to be part of the molecular observation strategy in order to generate near-real-time information on the occurrence of key species on-board and to complement NGS-based information on phytoplankton community composition with quantitative information on the occurrence of selected key species (Fig. 1). These approaches are necessary because of biases related to the amplification of the $18 \mathrm{~S}$ rDNA gene via PCR and because of uncertainties with respect to the copy number of the gene in the genome of different species (e.g., Zhu et al., 2005), which make it difficult to deduce species abundance based on NGS. We developed new molecular probes for relevant taxa that were major contributors in our NGS libraries or that were known from published literature to occur in the observation areas (North Sea and Arctic Ocean). The molecular probes were either used in combination with molecular sensors (Wollschläger et al., 2015), qPCR, or fluorescent in situ hybridization (Thiele et al., 2014). The data on species abundance, obtained from molecular sensors targeting either $18 \mathrm{~S}$ rDNA or $18 \mathrm{~S}$ rRNA, were evaluated with the results obtained from microscopic counts (Wollschläger et al., 2014). The molecular sensor targeting 18 S rRNA shows a robust linear relationship between molecular sensing signal and cell counts via microscopy. The positive evaluation results for the rRNA-based nucleic acid biosensor suggest excellent potential for the method to be used as a module in a molecular observation strategy. Here, the regular quantitative molecular monitoring would benefit from advantages like reduced effort (time, costs, and labor), and the high potential for automation of the methodology (Wollschläger et al., 2014). In this study we demonstrate the potential of quantitative PCR to better understand the biogeography and abun- 


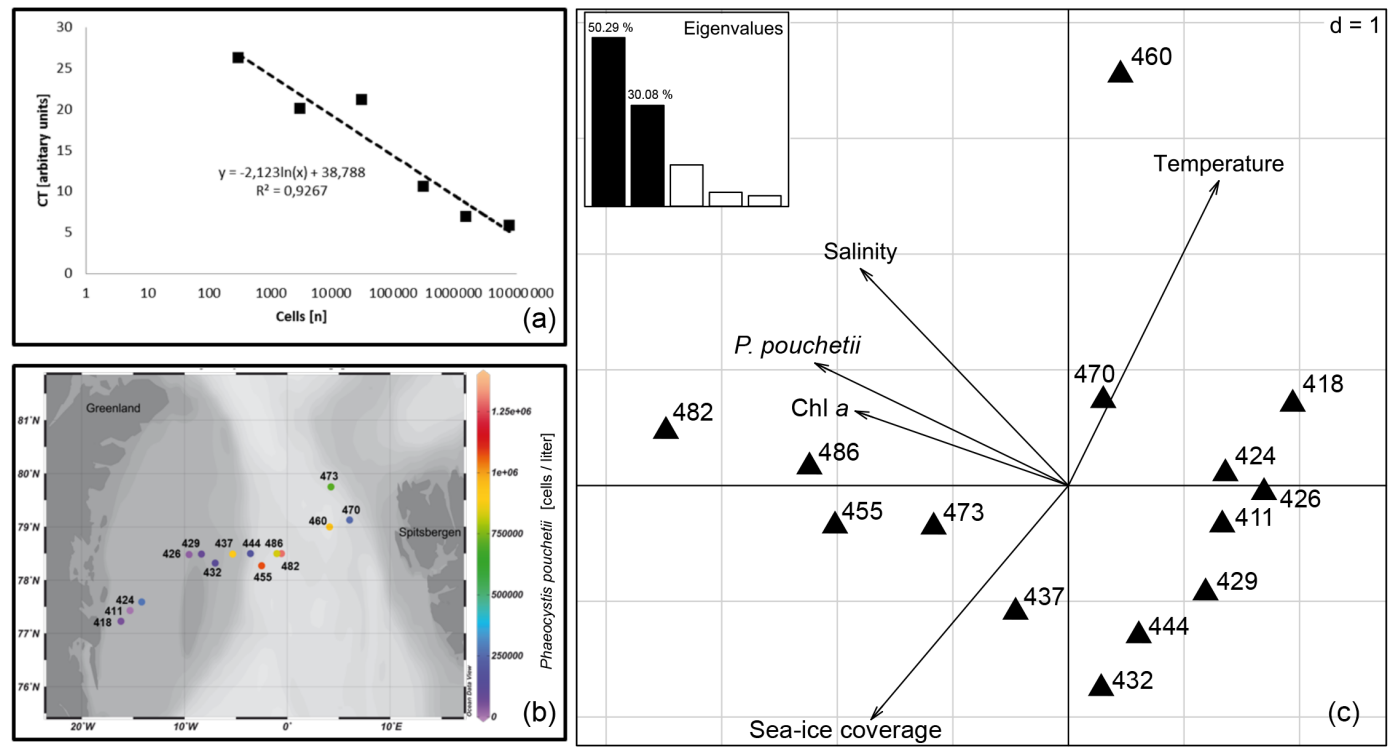

Figure 4. Assessment of Phaeocystis pouchetii in the Fram Strait. (a) Calibration of Phaeocystis pouchetii-specific qPCR assay with a dilution series of laboratory cultures. The CT value is significantly correlated with cell numbers. (b) Abundance of Phaeocystis pouchetii in the Fram Strait. The dots and the associated numbers represent sampling sites and associated station numbers of expedition ARKXXVIII(PS85) of RV Polarstern in summer 2014, while cell numbers/liter are reflected by different colors. (c) Principal component analysis including environmental parameters (temperature, salinity, Chl $a$ biomass, and sea-ice coverage) and abundance of Phaeocystis pouchetii. Triangles and associated numbers represent sampling sites and associated station numbers of expedition ARKXXVIII (PS85) of RV Polarstern in summer 2014. HG4 indicates the central station of the deep-sea long-term observatory Hausgarten in the Fram Strait. The eigenvalues indicate the proportion of variance explained by different dimensions in the diagram. The black bars in the histogram reflect the $x$ axis and the $y$ axis. Here $\sim 80 \%$ of variance is explained in this two-dimensional diagram of the PCA ( $x$ axis: $50.29 \% ; y$ axis: $30.08 \%$ ).

dance of Phaeocystis pouchetii in Arctic waters using a specific primer set for qPCR. The qPCR values were calibrated against defined numbers of laboratory cultures (Fig. 4) to allow quantification of Phaeocystis pouchetii via this method. During expedition PS85 of RV Polarstern in June 2014, we used qPCR on board to determine the abundance of Phaeocystis pouchetii on a transect through the Fram Strait at $\sim 79^{\circ} \mathrm{N}$ (Fig. 4). The results of our survey suggest that abundance of Phaeocystis pouchetii in the Fram Strait is determined by water mass properties such as salinity, ice coverage, and water temperature. Salinity is positively correlated with abundance of Phaeocystis pouchetii. The abundance of Phaeocystis pouchetii was higher in Atlantic waters, which are characterized by higher salinities in the range of 33$34 \mathrm{PSU}$, than in polar waters of the Fram Strait, which are characterized by salinities around 31 PSU. In Atlantic Waters the average cell number of Phaeocystis pouchetii was $\sim 3.5$ times higher than the average cell number in polar waters of the Fram Strait. Furthermore, Chl $a$ biomass appears to be correlated with abundance of Phaeocystis pouchetii. Our findings are in agreement with previous studies that reported blooms of Phaeocystis pouchetii in waters around Svalbard with cell abundances in a similar range as observed in this study (Wassmann et al., 2005). In 2012, we carried out a large-scale study to survey the biogeography of marine protists in the Arctic. This survey included a comprehensive NGS-based analysis of community composition along $79^{\circ} \mathrm{N}$ in the Fram Strait in June and later in the season in the Nansen Basin and Amundsen Basin. Overall, the findings of 2014, suggesting a positive correlation of Atlantic water properties (e.g., higher salinity and lower ice coverage with high abundance of Phaeocystis pouchetii), are in agreement with the previous study of 2012. This study also found a positive correlation in agreement with the findings of 2014 , even though sequence abundance of Phaeocystis pouchetii was more evenly distributed in the Fram Strait in 2012 (Metfies et al., 2016). This might be attributed to the complex current system in the area. Overall, qPCR carried out on board provided a near-real-time overview of the distribution of a protist key species during expedition PS85.

\section{Conclusions}

Here we introduce for the first time an integrated hierarchically organized molecular-based observation strategy that combines autonomous sampling with molecular analyses. It is a valuable tool to survey phytoplankton abundance and biodiversity in the desired high spatial and temporal resolution as well as at different levels of taxonomic resolution. The observation strategy is based on a combination of ship- 
based automated filtration, online measurements of oceanographic parameters, and different molecular analyses. On the one hand, our approach provides near-real-time information on phytoplankton key species abundance in relation to environmental conditions already on board. On the other hand, it provides detailed information on variability in the total phytoplankton community composition based on comprehensive, laboratory-based molecular analyses such as molecular fingerprinting methods and NGS. This information can be subsequently correlated with information on the physical and chemical marine environment and has excellent potential to complement other hierarchically organized observation strategies as described, for example, for the detection of marine hazardous substances and organisms (Zielinski et al., 2009). In summary, our molecular observation strategy is a significant contribution to refining regular assessment of consequences of ongoing environmental change for marine phytoplankton communities with respect to adequate spatial, temporal, and taxonomic resolution.

\section{Data availability}

Raw data of the molecular assessments presented in this publication were not deposited in public repositories, because there is no repository that archives raw data of molecular fingerprinting analyses or quantitative PCR.

Acknowledgements. This work was supported by the Coastal Observing System for Northern and Arctic Seas (COSYNA), institutional funds of the Alfred Wegener Institute for Polar and Marine Research, Bremerhaven, and funds of the Helmholtz Zentrum Geesthacht Centre for Materials and Coastal Research. The Initiative and Networking Fund of the Helmholtz Association financed the Helmholtz University Young Investigators Group PLANKTOSENS (VH-NG-500). We thank the crew of RV Polarstern for excellent support during the work at sea. Furthermore we thank Kerstin Oetjen, Swantje Rogge and Christiane Lorenzen for great technical assistance. Annegret Müller and Uwe John are acknowledged for excellent technical support of the fragment analysis.

The article processing charges for this open-access

publication were covered by a Research

Centre of the Helmholtz Association.

Edited by: O. Zielinski

Reviewed by: two anonymous referees

\section{References}

Acevedo-Trejos, E., Brandt, G., Steinacher, M., and Merico, A.: A glimpse into the future composition of marine phytoplankton communities, Front. Mar. Sci., 1, doi:10.1146/annurev-marine041911-111611, 2014.
Boersma, M., Gruner, N., Signorelli, N. T., Gonzalez, P. E. M., Peck, M. A., and Wiltshire, K. H.: Projecting effects of climate change on marine systems: is the mean all that matters?, P. R. Soc. B, 283, doi:10.1098/rspb.2015.2274, 2016.

Bowers, H. A., Brutemark, A., Carvalho, W. F., and Graneli, E.: Combining Flow Cytometry and Real-Time PCR Methodology to demonstrate consumption by Prymnesium parvum, J. Am. Water Resour. As., 46, 133-143, doi:10.1111/j.17521688.2009.00397.x, 2010.

Bresnan, E., Cook, K. B., Hughes, S. L., Hay, S. J., Smith, K., Walsham, P., and Webster, L.: Seasonality of the plankton community at an east and west coast monitoring site in Scottish waters, J. Sea Res., 105, 16-29, doi:10.1016/j.seares.2015.06.009, 2015.

Caron, D. A., Peele, E. R., Lim, E. L., and Dennett, M. R.: Picoplankton and nanoplankton and their trophic coupling in the surface waters of the Sargasso Sea south of Bermuda, Limnol Oceanogr., 44, 259-272, doi:10.4319/lo.1999.44.2.0259, 1999.

Comeau, A. M., Li, W. K. W., Tremblay, J. E., Carmack, E. C., and Lovejoy, C.: Arctic Ocean Microbial Community Structure before and after the 2007 Record Sea Ice Minimum, Plos One, 604, 6, doi:10.1038/srep00604, 2011.

de Vargas, C., Audic, S. Henry, N., Decelle, J., Mahe, F., Logares, R., Lara, E., Berney, C., Le Bescot, N., Probert, I., Carmichael, M., Poulain, J., Romac, S., Colin, S., Aury, J.-M., Bittner, L., Chaffron, S., Dunthorn, M., Engelen, S., Flegontova, O., Guidi, L., Horak, A., Jaillon, O., Lima-Mendez, G., Lukes J., Malviya, S., Morard, R., Mulot, M., Scalco, E., Siano, R., Vincent, F., Zingone, A., Dimier, C., Picheral, M., Searson, S., Kandels-Lewis, S., Acinas, S. G., Bork, P., Bowler, C., Gorsky, G., Grimsley, P., Hingamp, D., Iudicone, F., Not, H., Ogata, S., Pesant, J., Raes, M. E., Sieracki, S., Speich, N., Stemmann, L., Sunagawa, S., Weissenbach, J., Wincker, P., and Karsenti, E.: Eukaryotic plankton diversity in the sunlit ocean, Science, 348, 1261605, doi:10.1126/science.1261605, 2015.

Diercks, S., Metfies, K., and Medlin, L.K.: Development and adaptation of a multiprobe biosensor for the use in a semi-automated device for the detection of toxic algae, Biosens. Bioelectron, 23, 1527-1533, doi:10.1016/j.bios.2008.01.010, 2008a.

Diercks, S., Medlin, L. K., and Metfies, K.: Colorimetric detection of the toxic dinoflagellate Alexandrium minutum using sandwich hybridization in a microtiter plate assay, Harmful Algae, 7, 137145, doi:10.1016/j.hal.2007.06.005, 2008b.

Doney, S. C., Ruckelshaus, M., Duffy, J. E., Barry, J. P., Chan, F., English, C. A., Galindo, H. M., Grebmeier, J. M., Hollowed, A. B., Knowlton, N., Polovina, J., Rabalais, N. N., Sydeman, W. J., and Talley, L. D.: Climate Change Impacts on Marine Ecosystems, Annual Review of Marine Science, 4, 11-37, doi:10.1146/annurev-marine-041911-111611, 2012.

Field, C. B., Behrenfeld, M. J., Randerson, J. T., and Falkowski, P.: Primary production of the biosphere: Integrating terrestrial and oceanic components, Science, 281, 237-240, doi:10.1126/science.281.5374.237, 1998.

Hugenholtz, P.: Exploring prokaryotic diversity in the genomic era, Genome Biology, 3, doi:10.1186/gb-2002-3-2-reviews0003, 2002.

Kilias, E., Wolf, C., Noethig, E.-M., Peeken, I., and Metfies, K.: Protist distribution in the Western Fram Strait in summer, J. Phycol., 49, 996-1010, doi:10.1111/jpy.12109, 2013. 
Kilias, E., Kattner, G., Wolf, C., Frickenhaus, S., and Metfies, K.: A molecular survey of protist diversity through the central Arctic Ocean, Polar Biol., 61, 569-579, doi:10.1007/s00300-014-15195, 2014a.

Kilias, E. S., Noethig, E.-M., Wolf, C., and Metfies, K.: Picoeukaryote Plankton Composition off West Spitsbergen at the Entrance to the Arctic Ocean, J. Eukaryot. Microbiol., 33, 23466, doi:10.1111/jeu.12134, 2014b.

Kilias, E. S., Peeken, I., and Metfies, K.: Protist diversity in Arctic Sea Ice and Melt pond aggregates obtained by pyrosequencing - a short insight, Polar Res., 13, 74-80, doi:10.3402/polar.v33.23466, 2014c.

Kilias, E. S., Wolf, C., and Metfies, K.: Characterizing variability in marine protist communities via ARISA fingerprints - a method evaluation, Limnol. Oceanogr.-Meth., 13, 74-80, doi:10.1002/lom3.10008, 2015.

Kraberg, A. C., Rodriguez, N., and Salewski, C. R.: Historical phytoplankton data from Helgoland Roads: Can they be linked to modern time series data?, J. Sea Res., 101, 51-58, doi:10.1016/j.seares.2015.03.004, 2015.

Leibold, M. A.: Resources and predators can affect the vertical distributions of zooplankton, Limnol. Oceanogr., 35, 938-344, doi:10.4319/lo.1990.35.4.0938, 1990.

Mackas, D. L., Denman, K. L., and Abbott, M. R.: Plankton Patchiness-Biology in the physical vernacular, B. Mar. Sci., 37, 652-674, 1985.

McQuatters-Gollop, A., Edwards, M., Helaouet, P., Johns, D. G., Owens, N. J. P., Raitsos, D. E., Schroeder, D., Skinner, J., and Stern, R. F.: The Continuous Plankton Recorder survey: How can long-term phytoplankton datasets contribute to the assessment of Good Environmental Status?, Estuar. Coast. Mar. Sci., 162, 8897, doi:10.1016/j.ecss.2015.05.010, 2015.

Mellard, J. P., Yoshiyama, K., Litchman, E., and Klausmeier, C. A.: The vertical distribution of phytoplankton in stratified water columns, J. Theor. Biol., 269, 16-30, doi:10.1016/j.jtbi.2010.09.041, 2011.

Medlin, L., Elwood, H. J., Stickel, S., and Sogin, M.L.: The characterization of enzymatically amplified eukaroytic 16S-like rRNA coding regions, Gene, 71, 491-499, doi:10.1016/03781119(88)90066-2, 1988.

Metfies, K. and Medlin, L. K.: Refining cryptophyte identification with DNA-microarrays, J. Plankton Res., 29, 1071-1075, doi:10.1093/plankt/fbm080, 2007.

Metfies, K., Gescher, C., Frickenhaus, S., Niestroy, R., Wichels, A., Gerdts, G., Knefelkamp, B., Wiltshire, K., and Medlin, L.: Contribution of the class Cryptophyceae to phytoplankton structure in the German Bight, J. Phycol., 46, 1152-1160, doi:10.1111/j.1529-8817.2010.00902.x, 2010.

Metfies, K., von Appen, W. J., Kilias, E., Nicolaus, A., and Noethig, E. M.: Biogeography and photosynthetic biomass of arctic marine pico-eukaroytes during summer of the record sea ice minimum 2012, Plos One, 11, e0148512, doi:10.1371/journal.pone.0148512, 2016.

Nehring, S.: Establishment of thermophilic phytoplankton species in the North Sea: biological indicators of climatic changes?, ICES J. Mar. Sci., 55, 818-823, doi:10.1006/jmsc.1998.0389, 1998.
Petersen, W.: FerryBox systems: State-of-the-art in Europe and future development, J. Marine Syst., 140, 4-12, doi:10.1016/j.jmarsys.2014.07.003, 2014.

Quast, C., Pruesse, E., Yilmaz, P., Gerken, J., Schweer, T., Yarza, P., Peplies, J., and Gloeckner, F. O.: The SILVA ribosomal RNA gene database project: improved data processing and web-based tools, Nucleic Acids Res., 41, D590-D596, doi:10.1093/nar/gks1219, 2013.

Soltwedel, T.: HAUSGARTEN: multidisciplinary investigations at a deep-sea, long-term observatory in the Arctic Ocean, Oceanography, 18, 15, doi:10.5670/oceanog.2005.24, 2005.

Sunagawa, S., Coelho, L. P., Chaffron, S., Kultima, J. R., Labadie, K., Salazar, G., Djahanschiri, B., Zeller, G., Mende, D. R., Alberti, A., Cornejo-Castillo, F. M., Costea, P. I., Cruaud, C., d'Ovidio, F., Engelen, S., Ferrera, I., Gasol, J. M., Guidi, L., Hildebrand, F., Kokoszka, F., Lepoivre, C., Lima-Mendez, G., Poulain, J., Poulos, B. T., Royo-Llonch, M., Sarmento, H., Vieira-Silva, S., Dimier, C., Picheral, M., Searson, S., KandelsLewis, S., Bowler, C., de Vargas, C., Gorsky, G., Grimsley, N., Hingamp, P., Iudicone, D., Jaillon, O., Not, F., Ogata, H., Pesant, S., Speich, S., Stemmann, L., Sullivan, M. B., Weissenbach, J., Wincker, P., Karsenti, E., Raes, J., Acinas, S. G., and Bork, P.: Structure and function of the global ocean microbiome, Science, 348, 6237, doi:10.1126/science.1261359, 2015.

Thiele, S., Wolf, C., Schulz, I. K., Assmy, P., Metfies, K., and Fuchs, B. M.: Stable Composition of the Nanoand Picoplankton Community during the Ocean Iron Fertilization Experiment LOHAFEX, Plos One, 9, 0113244, doi:10.1371/journal.pone.0113244, 2014.

Toebe, K., Alpermann, T. J., Tillmann, U., Krock, B., Cembella, A., and John, U.: Molecular discrimination of toxic and non-toxic Alexandrium species (Dinophyta) in natural phytoplankton assemblages from the Scottish coast of the North Sea, Eur. J. Phycol., 48, 12-26, doi:10.1080/09670262.2012.752870, 2013.

Turnbaugh, P. J., Hamady, M., Yatsunenko, T., Cantarel, B. L., Duncan, A., Ley, R. E., Sogin, M. L., Jones, W. J., Roe, B. A., Affourtit, J. P., Egholm, M., Henrissat, B., Heath, A. C., Knight, R., and Gordon J. I.: A core gut microbiome in obese and lean twins, Nature, 457, 480-484, doi:10.1038/nature07540, 2009.

Ussler, W., Preston, C., Tavormina, P., Pargett, D., Jensen, S., Roman, B., Marin, R., Shah, S. R., Girguis, P. R., Birch, J. M., Orphan, V., and Scholin C.: Autonomous Application of Quantitative PCR in the Deep Sea: In Situ Surveys of Aerobic Methanotrophs Using the Deep-Sea Environmental Sample Processor, Environ. Sci. Technol., 47, 9339-9346, doi:10.1021/es4023199, 2013.

Wassmann, P., Ratkova, T., and Reigstad, M.: The contribution of single and colonial cells of Phaeocystis pouchetii to spring and summer blooms in the north-eastern North Atlantic, Harmful Algae, 4, 823-840, doi:10.1016/j.hal.2004.12.009, 2005.

Wiltshire, K. H., Kraberg, A., Bartsch, I., Boersma, M., Franke, H.-D., Freund, J., Gebuehr, C., Gerdts, G., Stockmann, K., and Wichels, A.: Helgoland Roads, North Sea: 45 Years of Change, Estuar. Coasts, 33, 295-310, doi:10.1007/s12237-009-9228-y, 2009.

Woese, C. R.: Bacterial Evolution, Microbiol. Rev., 51, 221-271, 1987.

Wolf, C., Frickenhaus, S., Kilias, E. S., Peeken, I., and Metfies, K.: Regional variability in eukaryotic protist commu- 
nities in the Amundsen Sea, Antarct. Sci., 25, 741-751, doi:10.1017/S0954102013000229, 2013.

Wolf, C., Kilias, E. S., and Metfies, K.: Evaluating the potential of $18 \mathrm{~S}$ rDNA clone libraries to complement pyrosequencing data of marine protists with near full-length sequence information, Mar. Biol. Res., 10, 771-780, doi:10.1080/17451000.2013.852685, 2014a.

Wolf, C., Frickenhaus, S., Kilias, E. S., Peeken, I., and Metfies, K.: Protist community composition in the Pacific sector of the Southern Ocean during austral summer 2010, Polar Biol., 37, 375-389, doi:10.1007/s00300-013-1438-x, 2014b.

Wollschläger, J., Nicolaus, A., Wiltshire, K. H., and Metfies, K.: Assessment of North Sea phytoplankton via molecular sensing: a method evaluation, J. Plankton Res., 36, 695-708, doi:10.1093/plankt/fbu003, 2014.
Wollschläger, J., Wiltshire, K. H., Petersen, W., and Metfies, K.: Analysis of phytoplankton distribution and community structure in the German Bight with respect to the different size classes, J. Sea Res., 99, 83-96, doi:10.1016/j.seares.2015.02.005, 2015.

Zhu, F., Massana, R., Not, F., Marie, D., and Vaulot, D.: Mapping of picoeucaryotes in marine ecosystems with quantitative PCR of the 18S rRNA gene, FEMS Microbiol. Ecol., 52, 79-92, doi:10.1016/j.protis.2012.11.006, 2005.

Zielinski, O., Busch, J. A., Cembella, A. D., Daly, K. L., Engelbrektsson, J., Hannides, A. K., and Schmidt, H.: Detecting marine hazardous substances and organisms: sensors for pollutants, toxins, and pathogens, Ocean Sci., 5, 329-349, doi:10.5194/os5-329-2009, 2009. 